\title{
Effects of Biochar Application on Soil Organic Carbon Mineralization during Drying and Rewetting Cycles
}

\author{
Gang Xu, ${ }^{\mathrm{a}, \mathrm{b}, *}$ Jiawei Song, ${ }^{\mathrm{b}, \mathrm{c}}$ Yang Zhang, ${ }^{\mathrm{b}, \mathrm{c}}$ and Yingchun Lv ${ }^{\mathrm{a}, \mathrm{b}}$ \\ Intense droughts and extreme precipitation events are likely to occur more \\ frequently with global climate change. These drying-rewetting (DW) cycles \\ affect the soil carbon $(\mathrm{C})$ cycle. Biochar addition are reported to affect SOC \\ mineralization and soil organic carbon (SOC) storage. However, the \\ effects of biochar application on SOC mineralization during DW cycles are \\ poorly understood. Two wheat straw (WS25) biochar produced at $300{ }^{\circ} \mathrm{C}$ \\ (WS300) and $600{ }^{\circ} \mathrm{C}$ (WS600) were used to explore the effects of biochar \\ on SOC mineralization under artificial DW cycles as compared to constant \\ moisture (CM). It was found that biochar had different effects on SOC \\ mineralization depending on biochar type or drying/rewetting period of DW \\ cycles. Just like CK and WS25, WS600 application decreased SOC \\ mineralization under DW cycles compared to CM. To some extent, SOC \\ mineralization during DW cycles was similar to CM for WS300. The results \\ suggested that WS300 addition diminished the reducing effect of DW cycle \\ on SOC mineralization. In addition, biochar exhibited different effects on \\ SOC mineralization depending on the drying and rewetting period under \\ DW cycles. Biochar (WS300) addition during the drying period had less \\ effect on SOC mineralization but increased the flush effect of SOC \\ mineralization during the rewetting period. In conclusions, biochar \\ application significantly affect SOC mineralization following DW cycles.
}

Keywords: Biochar; Drying-rewetting cycles; Organic carbon mineralization; Saline soil

\begin{abstract}
Abbreviations:
C, carbon; SOC, soil organic carbon; $C M$, constant moisture; $\mathrm{DW}$, drying-rewetting cycles; $\mathrm{CO}_{2}$, carbon dioxide; $C M c, C$ mineralization during $C M$ event; $D W c$, the cumulative $C$ mineralization during $D W$ cycles; $\delta$, the percentage of deviation of $C$ mineralization during $D W$ cycles relative to $C M$ events

Contact information: a: College of Geography and Tourism, Qufu Normal University, Rizhao 276826, China; $b$ : Yantai Institute of Coastal Zone Research, Chinese Academy of Sciences, Yantai 264003, China; c: University of Chinese Academy of Sciences, Beijing 100049, China;

*Corresponding author: gxu@yic.ac.cn
\end{abstract}

\section{INTRODUCTION}

Biochar is a carbon-rich organic material produced by pyrolysis of organic materials under anoxic or hypoxic conditions (Glaser et al. 2009). Biochar is porous, has a large specific surface area and strong adsorption capabilities for nutrient or pollutants (Atkinson et al. 2010). Biochar effectively decreases soil bulk density and favours the formation of soil microaggregates, thereby improving soil structure and increasing the utilization rate of water and fertilizers (Biederman and Harpole 2013). Biochar also provides shelter for soil microorganisms and promotes the proliferation of microbial communities (Atkinson et al. 2010). Biochar contains mineral nutrients and it can be beneficial for plant growth and reduce additional chemical fertilizers (Liu et al. 2013). More importantly, biochar addition significantly increases crop yield in low to moderate 
fertility soils. As a result, biochar has attracted attention in agriculture, environment, and energy fields in recent years (Lehmann 2007; Major et al. 2010).

Soil organic carbon (SOC) is a key factor affecting soil fertility and crop yield. Biochar has a carbon (C) content of 60 to $91 \%$, and most of the C exists in the form of inert aromatic C (Enders et al. 2012). This $C$ has relatively stable physiochemical properties, strong resistance to biological degradation, and persists for a long time in soil (Glaser et al. 2009). Addition of biochar to soil can increase the SOC content. The magnitude of the increase is dependent on the amount of biochar added and its stability (Woolf et al. 2010). Kimetu et al. (2010) reported that biochar application significantly decreased SOC loss as compared with green manure because of the large amount of easily degraded organic matter contained in green manure. However, some studies show that biochar addition increased the degradation of the original SOC in a short time (Wardle et al. 2008). Different results may be caused by the different biochar properties, soil type, environmental factors, and the duration of biochar addition into soil (Zheng et al. 2018).

Soil moisture affects SOC mineralization and soil microbial respiration (Chow et al. 2006). Relatively lower soil moisture decreases the tendency for soluble matter in soil to diffuse and does not provide sufficient nutrients for microorganisms (Chowdhury et al. 2011), which affects SOC mineralization. It was found that the soil microbial community and activity greatly decreased after $14 \mathrm{~d}$ of soil drying (Pulleman and Tietema 1999). However, excessive moisture, such as flooding, will limit the growth of microbial communities due to anaerobic conditions (Mavi and Marschner 2012), and this will decrease the rate of SOC mineralization (Xiang et al. 2008). In recent years, with global climate change, intense droughts and extreme precipitation events are likely to occur more and more frequently. As a result, soil moisture generally experiences drying-retting (DW) cycles which affects soil microbial activity and SOC mineralization. DW cycles can increase SOC mineralization, resulting in increased $\mathrm{CO}_{2}$ emission into the atmosphere (Fierer and Schimel, 2003). However, the effects of biochar on SOC under DW cycles have not been fully understood. Coastal saline soil was selected for this work. It had relatively low SOC content. This study included (1) effects of different biochar on SOC mineralization in soil following DW cycles and CM events; and (2) biochar addition on SOC mineralization during drying and rewetting period following DW cycles.

\section{EXPERIMENTAL}

\section{Materials}

The surface ( 0 to $20 \mathrm{~cm}$ ) saline soil (Calcaric-Fluvisol) was collected in the Yellow River delta $\left(37^{\circ} 45^{\prime} 50^{\prime \prime} \mathrm{N}, 118^{\circ} 59^{\prime} 24^{\prime \prime} \mathrm{E}\right)$. After collection, gravel and plant debris were removed, and the soil was passed through a $2 \mathrm{~mm}$ sieve before storage at $4^{\circ} \mathrm{C}$. The soil $\mathrm{pH}$ was 8.3 and the SOC content was $4.7 \mathrm{mg} / \mathrm{g}$. The material used for biochar preparation was wheat straw. After the wheat straw was washed and impurities removed, it was dried to constant weight, crushed, and passed through a $2 \mathrm{~mm}$ sieve. Following this, the wheat straw was placed in a stainless-steel tank for air isolation. The straw material was charred using a muffle furnace (DRZ-4DAS electric-resistance furnace, Longkou, China). The charring temperatures were set to $300{ }^{\circ} \mathrm{C}$ and $600{ }^{\circ} \mathrm{C}$, respectively, and the charring time was $4 \mathrm{~h}$. Some physichemical properties of the soil and biochar are listed in Table 1. 


\section{Experimental Design}

Fresh sieved soil samples (equivalent to $200 \mathrm{~g}$ of dry soil) were mixed with wheat straw or biochar in a $1 \mathrm{~L}$ bottle to create four treatments: soil alone $(\mathrm{CK})$, wheat straw amended soil (69 $\mathrm{g} \cdot \mathrm{kg}^{-1}$, WS25,), lower temperature biochar amended soil $\left(20 \mathrm{~g} \cdot \mathrm{kg}^{-1}\right.$, WS300), and higher temperature biochar amended soil $\left(18 \mathrm{~g} \cdot \mathrm{kg}^{-1}, \mathrm{WS} 600\right)$. Each treatment had five replicates. WS25, WS300, and WS600 treatments had equal initial C content. Two conditions CM and DW cycles were set up for comparison. In total, 40 bottles were used in this study because first 20 bottles were used during CM treatment and the other 20 bottles were used during DW cycles. For the CM, water content was maintained at $70 \%$ WHC (water holding capacity) throughout the experiment by replenishing appropriate water. DW cycles were run three successive cycles, with each cycle containing a drying period and a rewetting period. The drying period (without water supplement) lasted for $7 \mathrm{~d}$, during which the water content was decreased from $70 \%$ WHC to $30 \%$ WHC. After drying period, the water content was added to $70 \%$ WHC to create the rewetting period $(7 \mathrm{~d})$. The bottles were placed in an incubator (RZH artificial climate incubator, Hangzhou Huier) for $25^{\circ} \mathrm{C}$ of open incubation. On days 2, 9, 12, 17, 21, 24, 27, 30, 33, 37, 40, 43, 46, 49, 52, 55, 59, and 63 of the experiment, gas chromatography was used to measure the amount of $\mathrm{CO}_{2}$ produced in each treatment. The mineralization rate and cumulative mineralized quantity of $\mathrm{CO}_{2}$ for each treatment was calculated.

\section{Methods}

\section{Data calculation and analysis}

The $\mathrm{CO}_{2}$ concentration was measured using a gas chromatograph (Agilent 7980A). Before sampling, the gases in the bottle were on the balance with outside air. The formula for calculation of the mineralization rate was,

$$
\beta=\rho \times(V / W) \times\left(d_{\mathrm{d}} / d_{\mathrm{t}}\right) \times(273 / T)
$$

where $\beta$ represents $\mathrm{CO}_{2}$ mineralization rate $\left(\mu \mathrm{g} \cdot \mathrm{g}^{-1} \cdot \mathrm{d}^{-1}\right), \rho$ represents $\mathrm{CO}_{2}$ density under standard conditions $\left(1.98 \mathrm{~g} \cdot \mathrm{L}^{-1}\right), V$ is the gas volume inside the incubation bottle (L), $W$ is soil sample mass $(\mathrm{g}) ; d_{\mathrm{d}} / d_{\mathrm{t}}$ is the rate of change of $\mathrm{CO}_{2}$ concentration $\left(\mu \mathrm{L} \cdot \mathrm{L}^{-1} \cdot \mathrm{d}^{-1}\right)$; and $T$ is the incubation temperature $(\mathrm{K})$.

For SOC mineralization affected by the DW cycles, the parameter $\delta$ was used to represent the percentage deviation of SOC mineralization during DW cycles over the CM process. The equation is as follows,

$$
\delta=(C M c-D W c) \times 100 / C M c
$$

where $\delta$ represents the percentage of deviation of SOC mineralization during DW cycles over the CM process; $C M c$ is the cumulative SOC mineralization during the CM process $\left(\mu \mathrm{g} \cdot \mathrm{g}^{-1}\right)$, and $D W c$ is the cumulative SOC mineralization during the DW cycles. Comparison of different treatment $\delta$ values was used to examine whether addition of biochar affected the SOC mineralization during the DW cycles.

\section{Statistical analysis}

One-way ANOVA was carried out using the SPSS computer package (SPSS Inc. 1999, Chicago, USA) for the data of SOC mineralization rate and soil microbial carbon content. Significant differences between means were determined using Duncan test, where differences were considered statistically significant at the $\mathrm{P}<0.05$ level. Microsoft Excel 2010 was used for data analysis and figure production. 


\section{RESULTS AND DISCUSSION}

\section{Biochar Effects on SOC Mineralization Rate under DW Cycles}

Figure 1 shows that the SOC mineralization rate was relatively higher for all treatments (except CK) in the first DW cycle than in the other cycles.
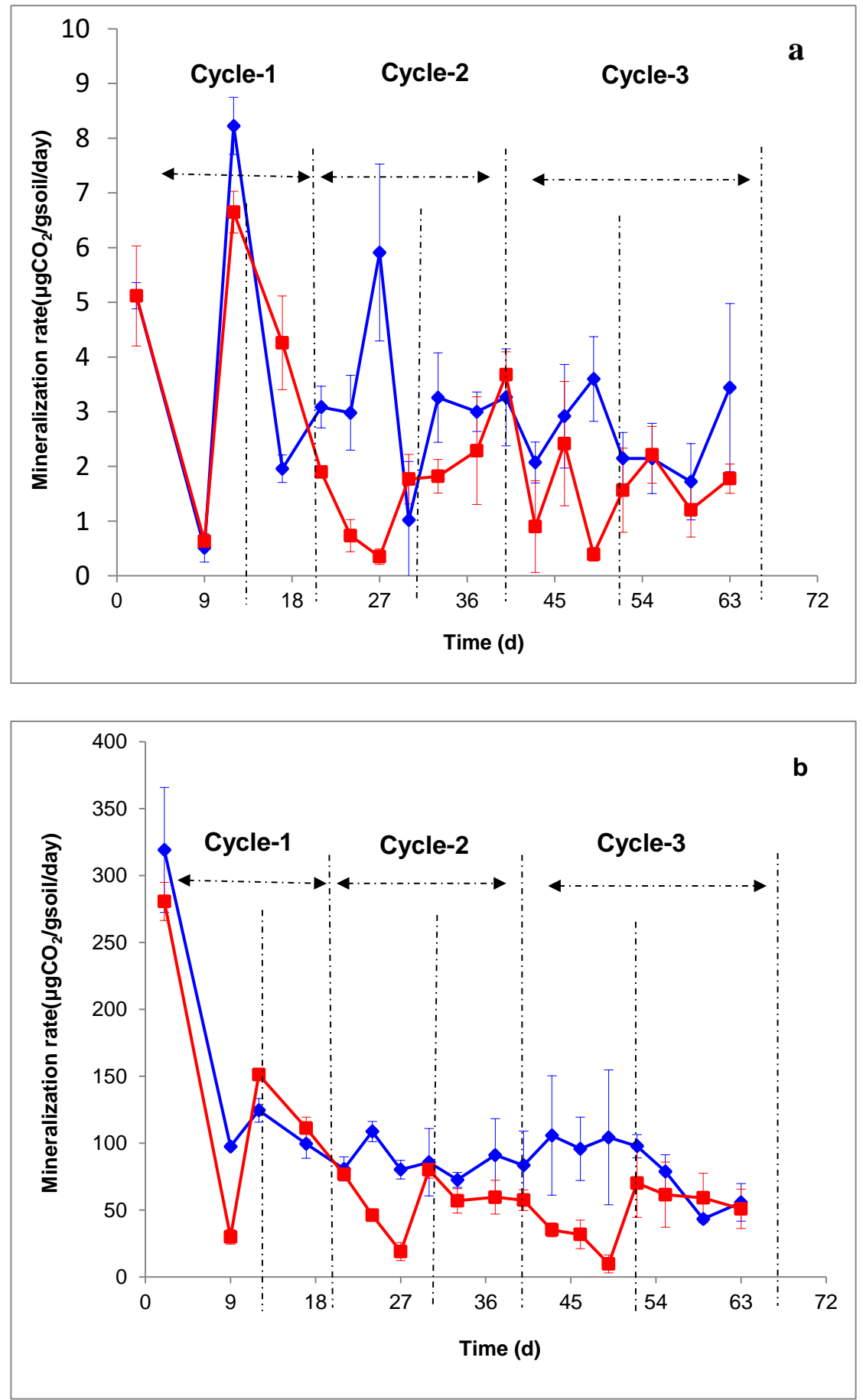

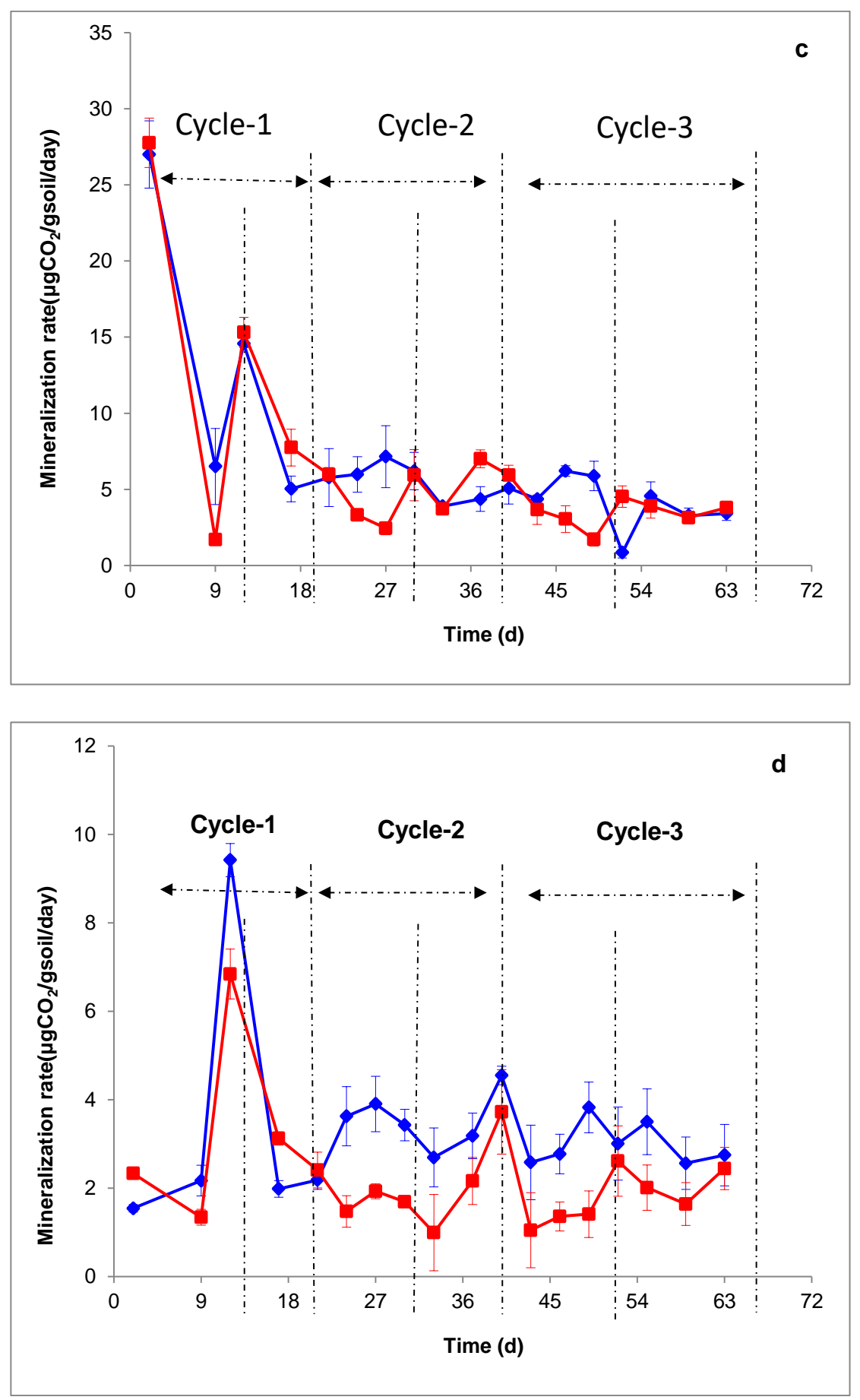

Fig. 1. Effects of drying-rewetting cycles on SOC mineralization rates in the treatments of (a) CK, (b) WS25, (c) WS300, (d) WS600. - indicates constant moisture, - indicates drying-rewetting cycles. Vertical bars represent the standard deviation of the organic carbon mineralization rates with 5 replicates.

With increasing incubation time, mineralization rate gradually decreased and stabilized. As is shown in Fig. 1, addition of WS25 significantly increased the SOC mineralization rate, possibly due to the higher level of easily oxidizable $\mathrm{C}$ in wheat straw (Sun et al. 2014). Addition of WS300 increased SOC mineralization rate within a short period of time, but the rate was similar to the control in the long term. The trend of SOC 
mineralization rate by WS600 was similar to the CK. These data demonstrate that biochar addition greatly increased SOC content and significantly decreased the SOC mineralization rate compared with WS25.

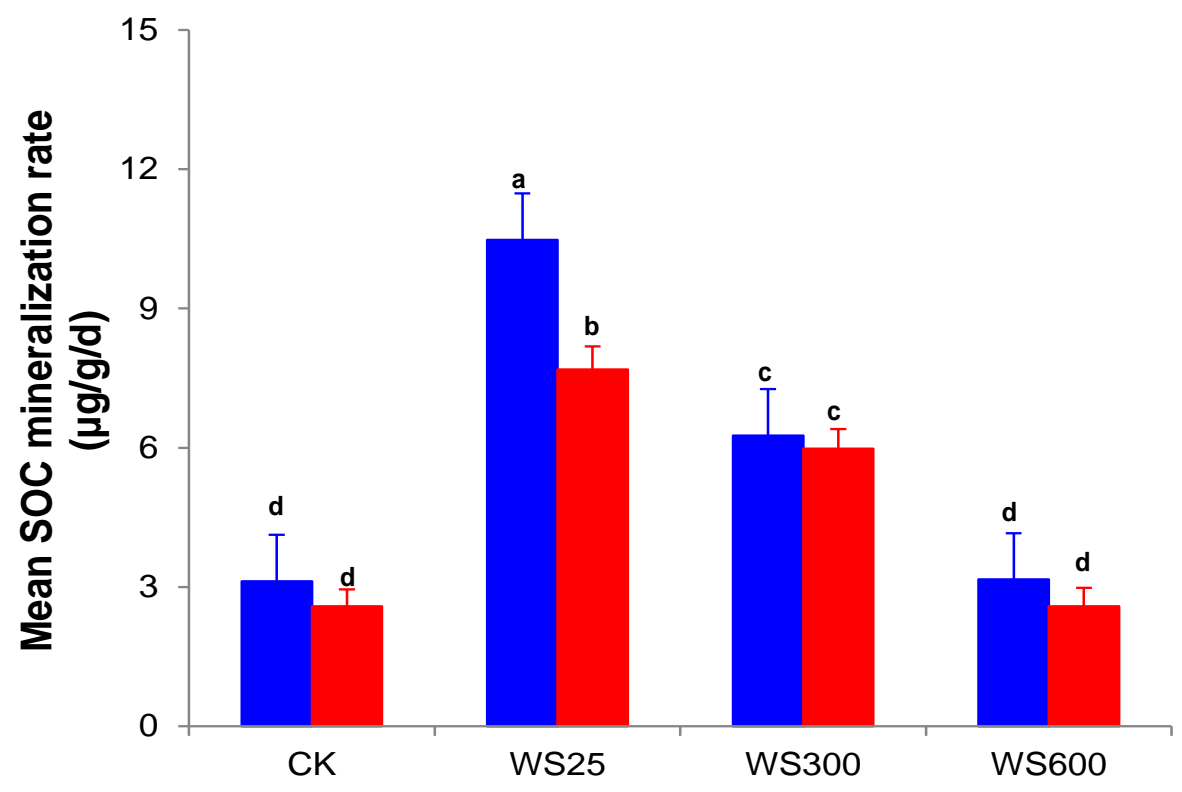

Fig. 2. The mean SOC mineralization rates in different treatment (WS25 indicates $1 / 10$ of real value). - indicates constant moisture, $\mathbf{n}$ indicates drying-rewetting cycles. Vertical bars represent the standard deviation of the mean organic carbon mineralization rates with 5 replicates. Different letters indicate significant differences between the treatments $(P<0.05)$.

Compared with CM conditions, the SOC mineralization rate during the drying period of DW cycles rapidly decreased with decreasing soil moisture. It has been found that drying inhibits soil microbial activity or even caused death of these microorganisms under extreme drought (Lehmann et al. 2011; Mavi and Marschner 2012). The reduced soil microbial activity significantly decreases degradation of SOC (Yang et al. 2016). In addition, drying limits the diffusion of $\mathrm{SOC}$, and this results in decreasing $\mathrm{CO}_{2}$ production (Franzluebbers et al. 1994; Chowdhury et al. 2011).

When dried soil undergoes rewetting, the SOC mineralization rate (flush of $\mathrm{CO}_{2}$ ) significantly increased relative to the mineralization rate measured pre-dry down levels (Franzluebbers et al. 2000; Fierer and Schimel 2003). For three successive DW cycles, the proportion of flushed of $\mathrm{CO}_{2}$ following rewetting of dried soil were $406 \%, 322 \%$, and $612 \%$ for WS25, $802 \%, 143 \%$, and $165 \%$ for WS300, and $411 \%,-12 \%$, and $85 \%$ for WS600. The observation suggested that the size of flush of $\mathrm{CO}_{2}$ significantly decreased with increasing frequency of DW cycles. This phenomenon of enhanced $\mathrm{CO}_{2}$ emission after a rewetting event is likely due to the stimulation of inhibited microorganisms during the drying phase and the rapid release of previously protected labile organic matter (Denef et al. 2001; Fierer and Schimel 2003; Mavi and Marschner 2012). 
Table 1. Physicochemical Characteristics of the Soil and Biochar

\begin{tabular}{|l|l|l|l|l|l|l|}
\hline & $\mathrm{pH}$ & $\begin{array}{l}\mathrm{EC} \\
\left(\mu \mathrm{cm} \mathrm{cm}^{-1}\right)\end{array}$ & $\begin{array}{l}\text { TOC } \\
\left(\mathrm{g} \mathrm{kg}^{-1}\right)\end{array}$ & $\begin{array}{l}\mathrm{N} \\
\left(\mathrm{g} \mathrm{kg}^{-1}\right)\end{array}$ & $\begin{array}{l}\mathrm{LOM} \\
\left(\mathrm{g} \mathrm{kg}^{-1}\right)^{*}\end{array}$ & $\begin{array}{l}\text { Ash } \\
(\%)\end{array}$ \\
\hline Soil & 7.0 & 500 & 8 & 0.9 & 3 & - \\
\hline WS25 & 6.8 & 2770 & 375 & 17.0 & 246 & 6.1 \\
\hline WS300 & 6.9 & 3975 & 643 & 14.8 & 133 & 10.1 \\
\hline WS600 & 9.6 & 6495 & 702 & 10.0 & 68 & 19.6 \\
\hline
\end{tabular}

It is interesting to note that addition of biochar decreased the rewetting of $\mathrm{CO}_{2}$ pulse, especially for second or third DW cycles. The size of the $\mathrm{CO}_{2}$ pulse depend on the size of the organic pool, the quality of organic matter, and the properties of the soil biota (Fierer and Schimel 2002). As was shown in Table 1, the content of decomposable labile organic matter followed the order of WS25 $>$ WS300 $>$ WS600. Decomposition of this labile component may explain the lower $\mathrm{CO}_{2}$ pulse for WS300 and WS600, relative to WS25 as previously reported (Yang et al. 2017). In addition, the enrichment process of biochar provides microorganisms with a shelter to resist drought condition and significantly stimulation of microbial activity did not occur after rewetting of drying soil (Fierer and Schimel 2002). This is consistent with changes in soil microbial biomass carbon (MBC) observed following rewetting of drying soil. As is shown in Fig. 3, the MBC content during $\mathrm{CM}$ process in control soil was $33.9 \pm 15.9 \mathrm{mg} \cdot \mathrm{kg}^{-1}$, which was significantly decreased to $8.2 \pm 2.6 \mathrm{mg} \cdot \mathrm{kg}^{-1}$ after DW cycles $(\mathrm{P}<0.05)$. The response of soil MBC to DW cycles was decreased when biochar addition into the soil. For example, the MBC of WS300 was statistically insignificant $(\mathrm{P}>0.05)$ in the CM condition $\left(20.4 \pm 5.1 \mathrm{mg} \cdot \mathrm{kg}^{-1}\right)$ and DW cycles $\left(27.1 \pm 1.7 \mathrm{mg} \cdot \mathrm{kg}^{-1}\right)$. The results suggest that biochar application decreased the effects of DW cycles on soil MBC and thereby led to reduce flush of $\mathrm{CO}_{2}$.

\section{Effects of Biochar Addition on Cumulative SOC Mineralization in Soil Under DW Cycles}

Table 2 shows that the cumulative SOC mineralization in soil subjected to DW cycles was lower than soil exposed to $\mathrm{CM}$ conditions. This indicated that the flush of $\mathrm{CO}_{2}$ in the rewetting period did not compensate for the reduction of $\mathrm{CO}_{2}$ during the drying period. DW cycles clearly decreased SOC mineralization and favoured the formation of organic matter in soil. For convenience, the parameter $\delta$ (Eq. 2), the percentage of deviation of cumulative SOC mineralization during DW cycles relative to CM condition, was used to represent the effects of DW cycles on SOC mineralization in treated samples. The $\delta$ values of three DW cycles were $12.8 \%, 22.8 \%$, and $25.9 \%$ for CK, $13.8 \%, 19.2 \%$, and $26.3 \%$ for WS25, 7.7\%, 9.0\%, and $8.7 \%$ for WS300, and $11.7 \%, 24.4 \%$, and $29.5 \%$ for WS600. This observation suggested that the $\mathrm{CO}_{2}$ flux subjected to DW treatment decreased with the frequency of DW cycles, as previously experienced. This pattern indicated that the microbial community may adjust to the water stress with increasing of DW cycles (Chowdhury et al. 2011). It is important to note that biochar application showed different effects on cumulative SOC mineralization, depending on the drying or rewetting period in DW cycles. All treatments decreased cumulative SOC mineralization during the drying period. The $\delta$ values in the drying period of the three DW cycles were $22.3 \%, 16.2 \%$, and $29.3 \%$ for CK, $21.4 \%, 17.5 \%$, and $26.9 \%$ for WS $25,16.2 \%, 9.6 \%$, and $10.6 \%$ for WS300, $19.0 \%, 15.1 \%$, and $28.5 \%$ for WS600. 
Table 2. Changes of Cumulative Organic Carbon Mineralization for the Entire DW, Drying, and Rewetting Period Relative to CM for Different Treatments

\begin{tabular}{|c|c|c|c|c|}
\hline$\delta$ & CK & WS25 & WS300 & WS600 \\
\hline & \multicolumn{4}{|c|}{ Entire DW Period (\%) } \\
\hline First DW & 12.8 & 13.8 & 7.7 & 11.7 \\
\hline Second DW & 22.8 & 19.2 & 9.0 & 24.4 \\
\hline \multirow[t]{2}{*}{ Third DW } & 25.9 & 26.3 & 8.7 & 29.5 \\
\hline & \multicolumn{4}{|c|}{ Drying Period (\%) } \\
\hline First DW & 22.3 & 21.4 & 16.2 & 19.0 \\
\hline Second DW & 16.2 & 17.5 & 9.6 & 15.1 \\
\hline \multirow[t]{2}{*}{ Third DW } & 23.9 & 26.9 & 10.6 & 28.5 \\
\hline & \multicolumn{4}{|c|}{ Rewetting Period (\%) } \\
\hline First DW & 10.0 & 3.8 & -3.2 & 9.0 \\
\hline Second DW & 42.8 & 27.8 & 6.3 & 50.6 \\
\hline Third DW & 35.4 & 22.9 & -5.7 & 33.5 \\
\hline
\end{tabular}

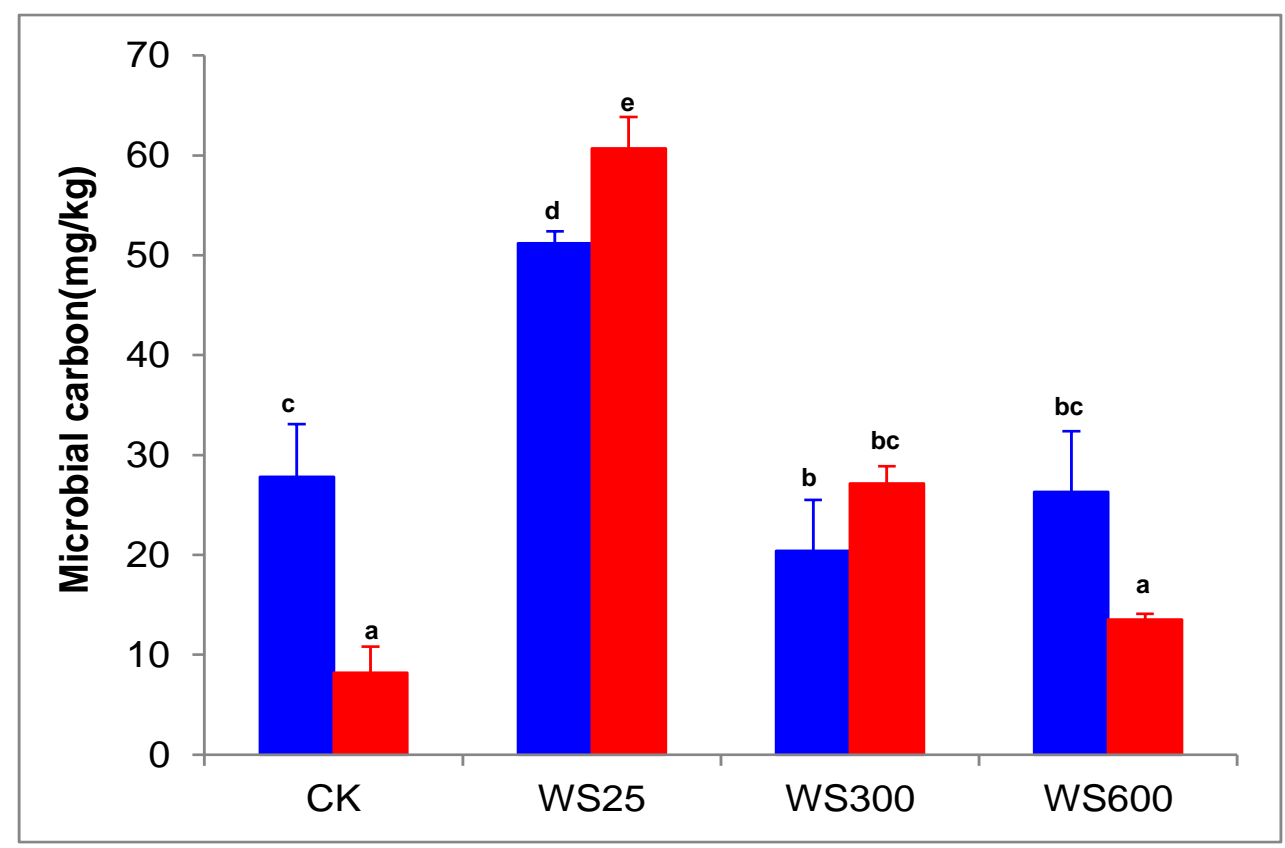

Fig. 3. Changes of soil microbial carbon content in different treatment. - indicates constant

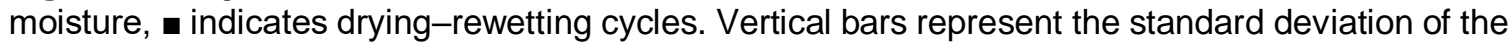
soil microbial carbon content with 3 replicates. Different letters indicate significant differences between the treatments $(P<0.05)$.

The data suggested that biochar application show non-significantly effects on cumulative SOC mineralization during the drying period compared with CK or WS25. 
Biochar application had been reported to increase the resistance of both the bacterial and fungal networks to drought stress. (Liang et al. 2014). Maybe the response of microorganism to drought with biochar application rely on soil type or biochar type (Mavi and Marschner 2012; Liang et al. 2014). Therefore, $\mathrm{CO}_{2}$ flux from biochar amended soils subject to drought stress needs further investigation.

In contrast to the drying period, the $\delta$ values in the rewetting period of the three DW cycles were $10.0 \%, 42.8 \%$, and $35.4 \%$ for CK, $3.8 \%, 27.8 \%$, and $22.9 \%$ for WS25, and $9.0 \%, 50.6 \%$, and $33.5 \%$ for WS600. As comparison, the $\delta$ values in three rewetting period for the WS300 were $-3.2 \%, 6.3 \%$, and $-5.7 \%$. This observation suggested that WS300 application increased the flush $\mathrm{CO}_{2}$ after rewetting of dried soil and reduced the difference of SOC mineralization between the DW cycles and CM conditions. The results suggested that WS300 can inhibit the effects of DW cycles on SOC mineralization but WS600 does not show similar effects. As previously discussed, the WS300 contained more labile organic matter; thus the DW cycles will release more physically protected soil organic matter and increase the size of the $\mathrm{CO}_{2}$ pulse (Fierer and Schimel, 2003; Mavi and Marschner 2012). As a comparison, WS600 had higher electrical conductivity (EC) relative to WS300 (Table 1); therefore WS600 application was expected to increase the salinity and reduce the ability of microbes to adjust to a high water potential following rewetting of dried soil (Yang et al. 2017).

\section{CONCLUSIONS}

1. This study showed that biochar addition had different effects on soil organic carbon (SOC) mineralization caused by drying and rewetting (DW) cycles. Biochar addition during the drying period had little effect on SOC mineralization but decreased the flush $\mathrm{CO}_{2}$ during the rewetting period.

2. During the rewetting period, low temperature biochar (WS300) inhibited the effects of the rewetting process on SOC mineralization, while high temperature biochar (WS600) had little effect. Therefore, low temperature biochar can be used to decrease the effects of DW cycles on SOC mineralization in saline soil.

\section{ACKNOWLEDGEMENTS}

This research was co-supported by the National Natural Science Foundation of China (Grant Nos. 41573120 and U1806215), the Key Deployment Project of Chinese Academy of Sciences (KFZD-SW-112), and the Science and Technology Service Network Initiative (KFJ-STS-ZDTP-023).

\section{REFERENCES CITED}

Atkinson, C. J., Fitzgerald, J. D., and Hipps, N. A. (2010). "Potential mechanisms for achieving agricultural benefits from biochar application to temperate soils: A review," Plant and Soil 337(1-2), 1-18. DOI: 10.1007/s11104-010-0464-5 
Biederman, L. A., and Harpole, W. S. (2013). "Biochar and its effects on plant productivity and nutrient cycling: A meta-analysis," Global Change Biology Bioenergy 5, 202-214. DOI: 10.1111/gcbb.12037

Chow, A. T., Tanji, K. K., Gao, S., and Dahlgren, R. A. (2006). “Temperature, water content and wet-dry cycle effects on DOC production and carbon mineralization in agricultural peat soils," Soil Biology and Biochemistry 38(3), 477-488. DOI: 10.1016/j.soilbio.2005.06.005

Chowdhury, N., Nakatani, A. S., Setia, R., and Marschner, P. (2011). "Microbial activity and community composition in saline and non-saline soils exposed to multiple drying and rewetting events," Plant and Soil 348, 103-113. DOI:10.1007/s11104-011-0918-4

Denef, K., Six, J., Bossuyt, H., Frey, S. D., Elliott, E. T., Mer-ckx, R. (2001). "Influence of dry-wet cycles on the interrelationship between aggregate, particulate organic matter, and microbial community dynamics," Soil Biology \& Biochemistry 33(12), 1599-1611. DOI: 10.1016/S0038-0717(01)00076-1

Enders, A., Hanley, K., Whitman, T., Joseph, S., and Lehmann, J. (2012). "Characterization of biochars to evaluate recalcitrance and agronomic performance," Bioresource Technology 114, 644-653. DOI: 10.1016/j.biortech.2012.03.022

Fierer, N., and Schimel, J. P. (2002). "Effects of drying-rewetting frequency on soil carbon and nitrogen transformations," Soil Biology and Biochemistry 34, 777-787. DOI: 10.1016/S0038-0717(02)00007-X

Fierer, N., and Schimel, J. P. (2003). "A proposed mechanism for the pulse in carbon dioxide production commonly observed following the rapid rewetting of a dry soil," Soil Science Society of America Journal 67(3), 798-805. DOI: 10.2136/sssaj2003.7980

Franzluebbers, K., Weaver, R. W., Juo, A. S. R., and Franzluebbers, A. J. (1994). "Carbon and nitrogen mineralization from cowpea plants part decomposing in moist and in repeatedly dried and wetted soil," Soil Biology and Biochemistry 26(10), 13791387. DOI: 10.1016/0038-0717(94)90221-6

Franzluebbers, A., Haney, R., Honeycutt, C., Schomberg, H., and Hons, F. (2000). "Flush of carbon dioxide following rewetting of dried soil relates to active organic pools," Soil Science Society of America Journal 64, 613-623. DOI:10.2136/sssaj2000.642613x

Glaser, B., Parr, M., Braun, C., and Kopolo, G. (2009). "Biochar is carbon negative," Nature Geoscience 2(1), 2. DOI: 10.1038/ngeo395

Lehmann, J. (2007). “A handful of carbon,” Nature 447, 143-144. DOI: 10.1038/447143a

Lehmann, J., Rillig, M. C., Thies, J., Masiello, C. A., Hockaday, W. C., and Crowley, D. (2011). "Biochar effects on soil biota - A review," Soil Biology and Biochemistry 43(9), 1812-1836. DOI: 10.1016/j.soilbio.2011.04.022

Liang, C., Zhu, X., Fu, S., Méndez, A., Gascó, G., and Paz-Ferreiro, J. (2014). "Biochar alters the resistance and resilience to drought in a tropical soil," Environmental Research Letters 9, 064013. DOI:10.1088/1748-9326/9/6/064013

Liu, X., Zhang, A., Ji, C., Joseph, S., Bian, R., Li, L., Pan, G., and Paz-Ferreiro, J. (2013). "Biochar's effect on crop productivity and the dependence on experimental conditions - A meta-analysis of literature data," Plant and Soil 373(1-2), 583-594. DOI: $10.1007 / \mathrm{s} 11104-013-1806-\mathrm{X}$

Major, J., Rondon, M., Molina, D., Riha, S. J., and Lehmann, J. (2010). "Maize yield and nutrition during 4 years after biochar application to a Colombian savanna oxisol," Plant and Soil 333(1-2), 117-128. DOI: 10.1007/s11104-010-0327-0 
Mavi, M. S., and Marschner, P. (2012). "Drying and wetting in saline and saline-sodic soils - effects on microbial activity, biomass and dissolved organic carbon," Plant and Soil 355(1-2), 51-62. DOI: 10.1007/s11104-011-1078-2

Pulleman, M., and Tietema, A. (1999). "Microbial C and N transformations during drying and rewetting of coniferous forest floor material," Soil Biology and Biochemistry 31(2), 275-285. DOI: 10.1016/S0038-0717(98)00116-3

Sun, J., Wang, B., Gang, X., and Shao, H. (2014). "Effects of wheat straw biochar on carbon mineralization and guidance for large-scale soil quality improvement in the coastal wetland," Ecological Engineering 62, 43-47. DOI: 10.1016/j.ecoleng.2013.10.014

Wardle, D. A., Nilsson, M. C., and Zackrisson, O. (2008). "Fire-derived charcoal causes loss of forest humus," Science 320(5876), 629-629. DOI: 10.1126/science.1154960

Woolf, D., Amonette, J. E., Streetperrott, F. A., Lehmann, J., and Joseph, S. (2010). "Sustainable biochar to mitigate global climate change," Nature Communications 1,56. DOI: $10.1038 /$ ncomms 1053

Xiang, S. R., Allen, D., Patriciaa, H., and Joshuap, S. (2008). "Drying and rewetting effects on $\mathrm{C}$ and $\mathrm{N}$ mineralization and microbial activity in surface and subsurface California grassland soils," Soil Biology and Biochemistry 40(9), 2281-2289. DOI: 10.1016/j.soilbio.2008.05.004

Yang, F., Lee, X., Theng, B. K., Wang, B., Cheng, J.,Wang, Q. (2017). "Effect of biochar addition on short-term $\mathrm{N}_{2} \mathrm{O}$ and $\mathrm{CO}_{2}$ emissions during repeated drying and wetting of an anthropogenic alluvial soil," Environmental Geochemistry and Health 39, 635647. DOI:10.1007/s10653-016-9838-9

Zheng, H., Wang, X., Luo, X., Wang, Z., and Xing, B. (2018). "Biochar-induced negative carbon mineralization priming effects in a coastal wetland soil: Roles of soil aggregation and microbial modulation," Science of the Total Environment 610-611, 951-960. DOI: 10.1016/j.scitotenv.2017.08.166

Article submitted: April 24, 2019; Peer review completed: August 14, 2019; Revised version received and accepted; October 29, 2019; Published: October 31, 2019.

DOI: 10.15376/biores.14.4.9957-9967 